\title{
Catalytic Hydrogenation Using Abnormal N-Heterocyclic Carbene Palladium Complexes: Catalytic Scope and Mechanistic Insights
}

Marion Heckenroth, ${ }^{[\mathrm{a}]}$ Vsevolod Khlebnikov, ${ }^{[\mathrm{b}]}$ Antonia Neels, ${ }^{[\mathrm{c}]}$ Peter Schurtenberger, ${ }^{[\mathrm{d}]}$ and Martin Albrecht*[a,b]

[a] Dr. M. Heckenroth, Prof. Dr. M. Albrecht

Department of Chemistry, University of Fribourg, Chemin du Musée 9, CH-1700 Fribourg, Switzerland,

[b] Mr. V. Khlebnikov, Prof. Dr. M. Albrecht*

UCD School of Chemistry \& Chemical Biology, University College Dublin, Belfield, Dublin 4, Ireland. Email: martin.albrecht@ucd.ie, Fax: +353-1-716-2501

[c] Dr. A. Neels

XRD Application Lab, CSEM, Rue Jaquet-Droz 1, CH-2002, Neuchâtel, Switzerland,

[d] Prof. Dr. P. Schurtenberger

Physical Chemistry, Center for Chemistry and Chemical Engineering, Lund University, SE-22100 Lund, Sweden 


\begin{abstract}
Palladium complexes containing abnormally bound C4-bound dicarbene ligands were exploited in catalytic alkene hydrogenation. Comparison to normally C2-bound homologues indicates that the carbene bonding mode is critically influencing the catalytic activity. Good catalytic performance in the hydrogenation of cis-disubstituted olefins and non-isomerizable terminal olefins under mild conditions $\left(\mathrm{RT}, 1\right.$ bar $\left.\mathrm{H}_{2}\right)$ was only observed when the carbene is abnormally bound to the palladium center. Detailed mechanistic investigations using dynamic light scattering in connection with time-dependent analysis of conversions, and also by performing substoichiometric catalytic experiments provide evidence that the catalysis is heterogeneous and that the abnormal carbene ligand has the role of an activator.
\end{abstract}

Keywords: carbene ligands - palladium - hydrogenation - mechanism of activation abnormal bonding 


\section{Introduction}

The metal-catalyzed hydrogenation of unsaturated substrates has been a classic domain of transition metal complexes comprising phosphine ligands. ${ }^{[1]} \mathrm{N}$-heterocyclic carbene (NHC) ligands, ${ }^{[2]}$ once been considered as substitutes of phosphines, ${ }^{[3]}$ have been considerably less successful in hydrogenation catalysis. ${ }^{[4]}$ This limitation of NHC complexes may be due, in parts, to the propensity of the carbene ligand to undergo reductive elimination reactions, ${ }^{[5]}$ despite the fact that the $\mathrm{M}-\mathrm{C}_{\mathrm{NHC}}$ bond is generally considered to have a high covalent character and thus to be relatively strong. Reductive elimination pathways are particularly relevant in catalytic transformations involving intermediates that comprise metal-bound hydrides, ${ }^{[6,7]}$ alkyl, ${ }^{[8]}$ or aryl groups. ${ }^{[9]}$

We have recently discovered that abnormal dicarbene palladium complexes, i.e. NHC-type ligands that coordinate to the metal center abnormally via the imidazolylidene $C 4 / 5$ rather than the normal C2 position, ${ }^{[10]}$ provide catalyst precursors for the hydrogenation of olefins. ${ }^{[1]}$ The abnormal bonding mode was assumed to be essential for this catalytic activity, ${ }^{[12]}$ since C4-bound NHCs are considerably stronger donors than their normal counterparts. ${ }^{[10,13]}$ This enhanced donor ability provides access to new reactivity pathways. Specifically, the high electron density imparted to the metal center is surmised to facilitate oxidative addition reactions, ${ }^{[14]}$ which are a key step in the metal-mediated activation of $\mathrm{H}_{2}{ }^{[15]}$

Here we report on our investigation of the scope and limitation, and specifically on the mode of action of the dicarbene palladium complexes 1-4. These studies lend further support that oxidative $\mathrm{H}_{2}$ addition is a limiting factor for catalyst activation, thus emphasizing the relevance of using strongly donating abnormal carbene ligands in catalyst design. Furthermore, evidence is provided that the hydrogenation is heterogeneous, thus indicating 
that the carbene ligand plays a role as activator, but not as spectator ligand in the catalytically active species.
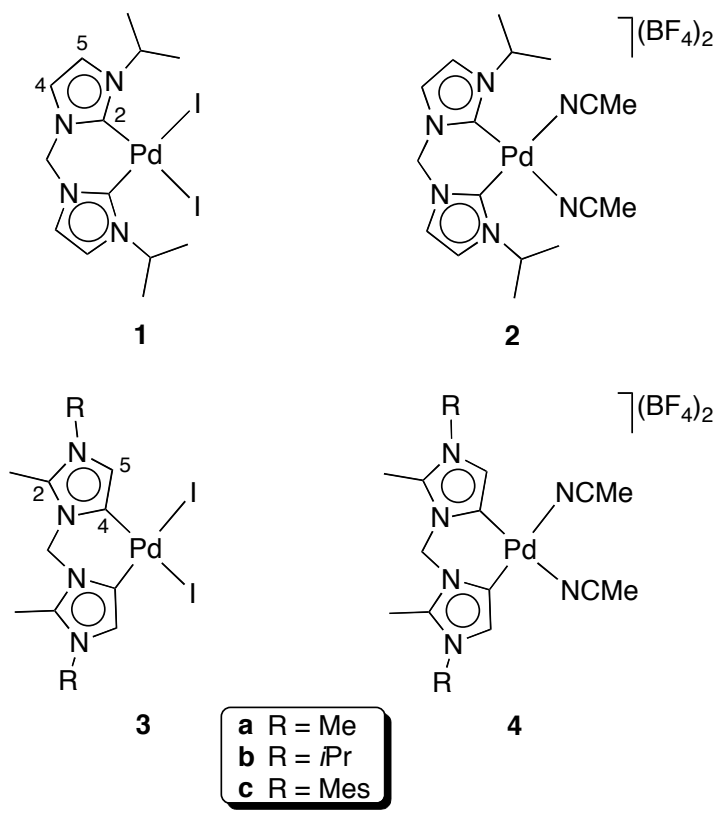

Figure 1. C2-bound dicarbene complexes 1 and 2 and the abnormal, C4-bound carbene homologues 3 and 4.

\section{Results and discussion}

Structural aspects. Complexes 1-4 were prepared according to known procedures. ${ }^{[1,16]}$ All solvento complexes $\mathbf{2}$ and $\mathbf{4 a - c}$ were analyzed by X-ray diffraction (Fig. 2, Table 1). Comparison of the structural parameters reveals only small differences between the normal complex 2 and the abnormal analogues 4a-c. The $\mathrm{Pd}-\mathrm{C}$ bond lengths are all similar and fit in the 1.96-2.00 $\AA$ range typically observed for Pd- $\mathrm{C}_{\mathrm{NHC}}$ bond lengths. ${ }^{[8,17]}$ The heterocyclic $\mathrm{C}-$ $\mathrm{C}$ bonds are only marginally longer in the C4-bound carbenes 4 than in the normal NHC. The bite angles $\mathrm{C} 1-\mathrm{Pd}-\mathrm{C} 7$ are larger in complexes $\mathbf{4}$ than in $\mathbf{2}$, though the $\mathrm{N}$-substituents seem to exert a stronger influence than the carbene bonding mode. Probably the largest structural difference consists of the dihedral angle between the palladium coordination plane and the heterocycles. In the abnormal carbene complexes $\mathbf{4}$, this angle is small (12-36 dihedral angles), indicating a relatively flat boat-type conformation of the six-membered metallacycle. In the normal carbene complex, the heterocycles are twisted out of the palladium coordination 
plane by about $42^{\circ}$, presumably as a direct consequence of the presence of ortho substituents at the carbene. Large twists likely shield the z- coordination

a)

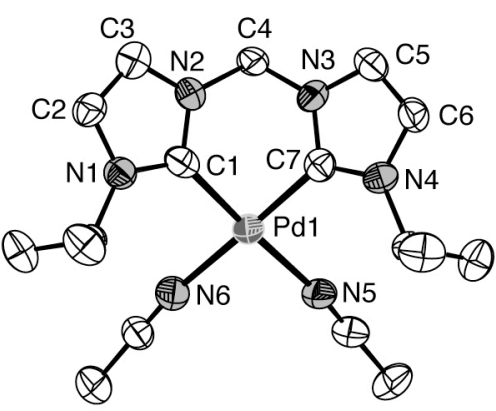

c)

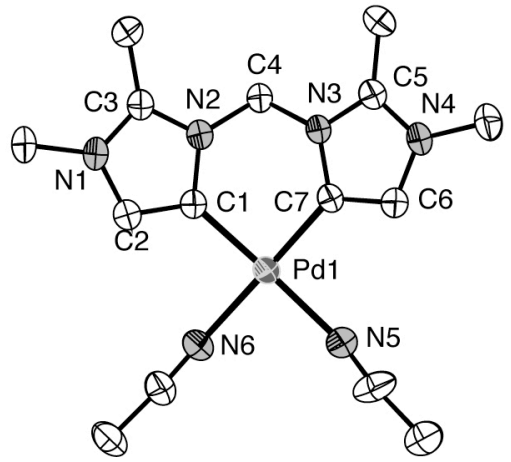

b)

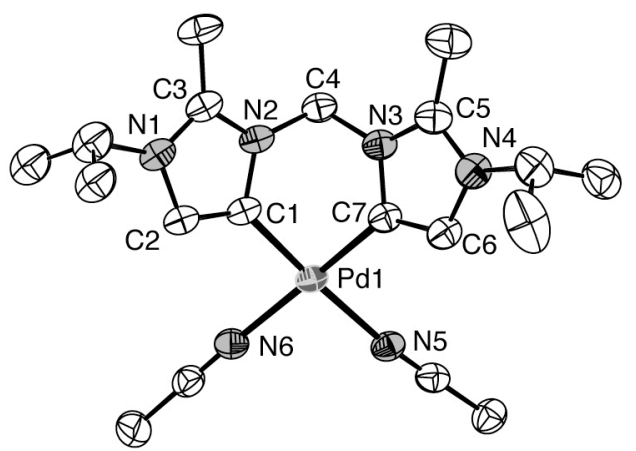

d)

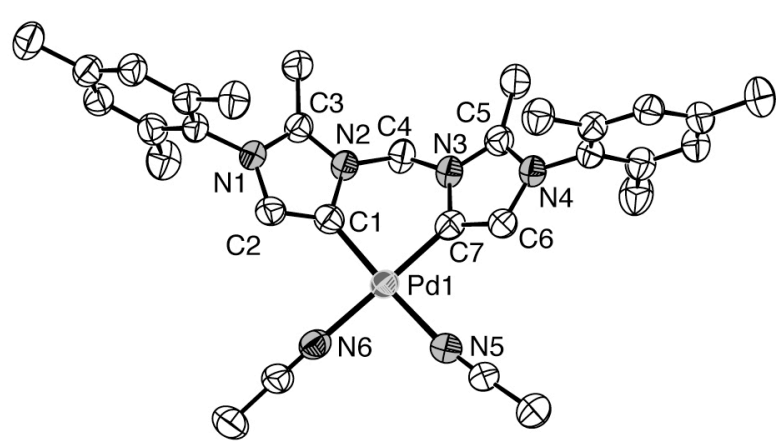

Figure 2. ORTEP representation of complexes 2 (a), $4 \mathbf{a}(\mathrm{b}), \mathbf{4 b}(\mathrm{c})$, and $\mathbf{4 c}$ (d) (50\% probability level, hydrogen atoms and co-crystallized solvent molecules omitted for clarity).

Table 1. Selected bond lengths $(\AA)$ and angles $\left(^{\circ}\right)$ in complexes $2, \mathbf{4 a}, \mathbf{4 b}, \mathbf{4 c}$.

\begin{tabular}{lllll}
\hline & $\mathbf{2}$ & $\mathbf{4 a}$ & $\mathbf{4 b}$ & $\mathbf{4 c}$ \\
\hline $\mathrm{Pd} 1-\mathrm{C} 1$ & $1.987(9)$ & $1.973(4)$ & $1.981(4)$ & $1.964(4)$ \\
$\mathrm{Pd} 1-\mathrm{C} 7$ & $1.994(9)$ & $1.974(4)$ & $1.973(4)$ & $1.975(4)$ \\
$\mathrm{Pd} 1-\mathrm{N} 5$ & $2.098(9)$ & $2.097(4)$ & $2.071(3)$ & $2.068(4)$ \\
$\mathrm{Pd} 1-\mathrm{N} 6$ & $2.076(8)$ & $2.074(4)$ & $2.072(4)$ & $2.065(4)$ \\
$\mathrm{C}_{\mathrm{imi}}-\mathrm{C}_{\mathrm{imi}}{ }^{[a]}$ & $1.341(14)$ & $1.358(6)$ & $1.356(6)$ & $1.362(5)$ \\
$\mathrm{C}^{\prime}{ }_{\mathrm{imi}}{ }^{-\mathrm{C}}{ }{ }_{\text {imi }}{ }^{[\mathrm{b}]}$ & $1.325(13)$ & $1.362(6)$ & $1.358(6)$ & $1.347(5)$ \\
$\mathrm{C} 1-\mathrm{Pd} 1-\mathrm{C} 7$ & $84.1(4)$ & $88.92(18)$ & $85.75(17)$ & $88.03(15)$ \\
$\mathrm{N} 5-\mathrm{Pd} 1-\mathrm{N} 6$ & $85.6(3)$ & $89.36(18)$ & $92.11(14)$ & $91.67(13)$ \\
$\mathrm{N} 2-\mathrm{C} 1-\mathrm{Pd} 1-\mathrm{C} 7$ & $42.7(9)$ & $12.6(4)$ & $34.7(3)$ & $22.5(3)$ \\
$\mathrm{C} 1-\mathrm{Pd} 1-\mathrm{C} 7-\mathrm{N} 3$ & $41.3(8)$ & $15.7(4)$ & $35.9(3)$ & $25.7(3)$ \\
\hline
\end{tabular}

${ }^{[\mathrm{a}]} \mathrm{C}_{\mathrm{imi}}-\mathrm{C}_{\mathrm{imi}}$ is $\mathrm{C} 2-\mathrm{C} 3$ for $\mathbf{2}$ and $\mathrm{C} 1-\mathrm{C} 2$ for $4 ;{ }^{[b]} \mathrm{C}^{\prime}{ }_{\mathrm{imi}}-\mathrm{C}^{\prime}{ }_{\mathrm{imi}}$ is $\mathrm{C} 5-\mathrm{C} 6$ for $\mathbf{2}$ and $\mathrm{C} 6-\mathrm{C} 7$ for 4. 
axis at palladium and may thus influence the reactivity. Notably, in solution the metallacycle is flexible in 4 (singlet of $\mathrm{NCH}_{2} \mathrm{~N}$ group at room temperature), ${ }^{[1]}$ while in $\mathbf{2}$ a rigid conformation is preserved even at $80{ }^{\circ} \mathrm{C}$ as evident from the $\mathrm{AB}$ pattern for the methylene protons. $^{[16 \mathrm{a}]}$

Catalytic hydrogenation. The catalytic activity of complexes 1-4 was evaluated in the hydrogenation of cyclooctene (coe) at $30{ }^{\circ} \mathrm{C}$ under $1 \mathrm{~atm} \mathrm{H}_{2}$. The solvento complexes 2 and 4 showed appreciable activity whereas the iodide analogues $\mathbf{1}$ and $\mathbf{3}$ were essentially inactive. Remarkably, in polar and weakly coordinating solvents such as alcohols, abnormal complex 4b was a significantly more active hydrogenation catalyst than the normal analogue 2 (Table 2, entries 1,2). Solvent screening showed that the most efficient solvent was EtOH in which the hydrogenation of coe was complete in less than $5 \mathrm{~h}$. Conversions were very low in nonpolar solvents like toluene, even after $24 \mathrm{~h}$, presumably due to the low solubility of the complexes (entries 3-5). In strongly coordinating solvents such as DMSO, DMF and MeCN, no conversion was observed (entries 6-8, see also below). Lowering the catalyst loading to 0.1 $\%$ gave slower conversion ( $74 \%$ after $4.5 \mathrm{~h}$, entry 10 ), and catalytic activity essentially ceased upon further lowering of the concentration of $\mathbf{4 b}$ to a 10,000:1 substrate/catalyst ratio (entry 11). Catalytic runs performed in $\mathrm{C}_{2} \mathrm{D}_{5} \mathrm{OD}$ did not reveal any significant incorporation of deuterium into coa (GC-MS), indicating $\mathrm{H}_{2}$ as the primary source of hydrogen.

Table 2. Catalytic activity of $\mathbf{4 a}$ and $\mathbf{2}$ for cyclooctene hydrogenation.

\begin{tabular}{|c|c|c|c|c|}
\hline \multirow[t]{2}{*}{ entry solvent } & \multirow[t]{2}{*}{$t / \mathrm{h}$} & \multirow[t]{2}{*}{ cat. load $^{[\mathrm{a}]}$} & \multicolumn{2}{|c|}{ Conversion $^{[\mathrm{b}]} / \%$} \\
\hline & & & cat. 2 & cat. 4b \\
\hline $\mathrm{MeOH}$ & $8(24)$ & $1 \%$ & 24 & $78(100)$ \\
\hline
\end{tabular}




\begin{tabular}{llllll}
\hline 2 & EtOH & 4.5 & $1 \%$ & 19 & 100 \\
3 & THF & $8(24)$ & $1 \%$ & 9 & $50(100)$ \\
4 & $\mathrm{CH}_{2} \mathrm{Cl}_{2}$ & $8(24)$ & $1 \%$ & 0 & $30(100)$ \\
5 & Toluene & $8(24)$ & $1 \%$ & 0 & $0(34)$ \\
6 & $\mathrm{DMF}$ & 24 & $1 \%$ & n.d. & 0 \\
7 & $\mathrm{MeCN}$ & 24 & $1 \%$ & n.d. & 0 \\
8 & DMSO & 24 & $1 \%$ & n.d. & 0 \\
9 & EtOH & 2.5 & $3 \%$ & n.d. & 100 \\
10 & EtOH & 4.5 & $0.1 \%$ & n.d. & 74 \\
11 & EtOH & 72 & $0.01 \%$ & n.d. & $<5$ \\
\hline
\end{tabular}

Conditions: cyclooctene $(2.0 \mathrm{mmol})$, EtOH $(6 \mathrm{~mL}), 30^{\circ} \mathrm{C}, 1 \mathrm{~atm} \mathrm{H}_{2}$.

${ }^{[a]}$ in mol equiv relative to cyclooctene; ${ }^{[b]}$ determined by GC, n.d. $=$ not determined, conversion after $24 \mathrm{~h}$ given in parentheses.

Time-dependent monitoring of the reaction under standard conditions ( 1 mol\% complex, $\mathrm{EtOH}$ ) indicated that the abnormal complexes $\mathbf{4 a}$ and $\mathbf{4 c}$ were slightly less active than $\mathbf{4 b}$ (Figure 3). Most strikingly, a long induction period $(>1 \mathrm{~h}$ ) was observed for all three complexes. The length of this induction period is strongly dependent on the reaction temperature. At $22{ }^{\circ} \mathrm{C}$ instead of $30{ }^{\circ} \mathrm{C}$, the induction was extended to nearly 2 h. ${ }^{[18]}$ At elevated temperatures $\left(55^{\circ} \mathrm{C}\right)$, significantly shorter $(<20 \mathrm{~min})$ induction was noticed, however, the temperature raise came at the expense of the overall rate and considerably longer times were required to achieve complete substrate conversion. 


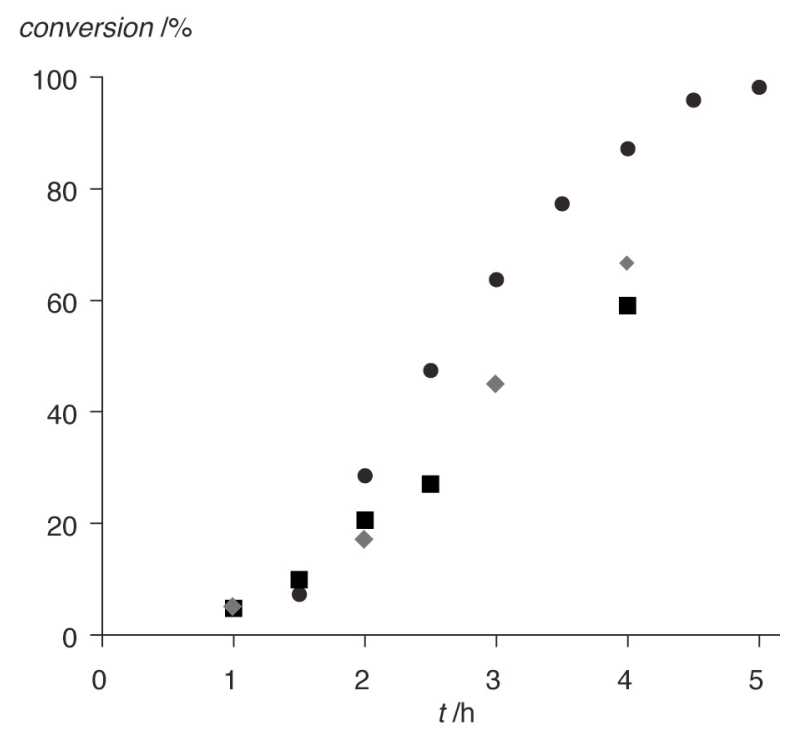

Figure 3. Time-conversion profile for cyclooctene hydrogenation using complexes 4a (squares), 4b (circles), and $4 \mathbf{c}$ (diamonds).

Substrates screening. The scope of complex $\mathbf{4 b}$ in the hydrogenation of double bonds was evaluated for various alkenes and also for unsaturated substrates with different functional groups (Table 3). The compiled results indicate a strong dependence of the catalytic activity on the nature of the olefin. The activity is reminiscent of that of Wilkinson's catalyst, with monosubstituted and terminal olefins being easiest to be reduced (entries 1, 2), followed by cis-olefins (entry 3), while trans olefins required much longer reaction times (entry 4). Trisubstituted olefins like 1-methylcyclohexene were also converted, albeit only slowly (26 $\mathrm{h}$, entry 5). Induction times were needed in each case as no conversion was observed during the first hour. The induction time for trans-stilbene was very long $(>7 \mathrm{~h})$, yet it was significantly reduced when $5 \mathrm{~mol} \%$ coe were added at the beginning of the reaction. Under these modified conditions, hydrogenation was complete after slightly more than $4 \mathrm{~h}$.

Table 3. Screening of different substrates using $\mathbf{4 b}$ as a catalyst. ${ }^{\text {[a] }}$

\begin{tabular}{llll}
\hline entry & substrate & $t / \mathrm{h}$ & conversion \\
\hline 1 & sStyrene & $2.5( \pm 0.7)$ & $>98 \%$ \\
2 & $\alpha$-methylstyrene & $2.9( \pm 1)$ & $>98 \%$
\end{tabular}




$$
\text { cyclooctene }
$$

trans-stilbene

methylcyclohexene

benzaldehyde

nitrobenzene

phenylacetylene

benzonitrile

$\begin{array}{ll}4.5( \pm 0.1) & >98 \% \\ 14 / 4^{\mathrm{b})} & >98 \% \\ 26 & >98 \% \\ 8 & >95 \% \\ 5( \pm 0.1) & >98 \% \\ 24 & >98 \% \\ & <2 \%\end{array}$

${ }^{[a]}$ General conditions: complex $4 \mathbf{b}(0.02 \mathrm{mmol})$, substrate $(2.0 \mathrm{mmol})$, EtOH $(6 \mathrm{~mL}), 30{ }^{\circ} \mathrm{C}, 1 \mathrm{~atm} \mathrm{H}_{2}$. b) coe $(0.1 \mathrm{mmol})$ added as promotor. c) in THF $(6 \mathrm{~mL})$

Allylbenzene constituted a special case since hydrogenation to propylbenzene was preceded by an isomerization process including the formation of $\beta$-methylstyrene via double bond migration. Selective formation of the trans-olefin intermediate was indicated by the large coupling constant ${ }^{3} J_{\mathrm{HH}}=16.1 \mathrm{~Hz}$ of the doublet at $\delta 6.40$ in the ${ }^{1} \mathrm{H}$ NMR spectrum. Similar isomerization processes were observed also with more complex substrates like carvone (Scheme 1). Under standard hydrogenation conditions, complex 4 induced a double bond isomerization to yield 5-isopropyl-2-methylphenol ${ }^{[19]}$ without further reaction.

\section{Scheme 1}<smiles>C=C(C)C1CC=C(C)C(=O)C1</smiles><smiles>CCO</smiles><smiles>Cc1ccc(C(C)C)cc1O</smiles>

carvone 5-isopropyl2-methylphenol

Functional groups were reduced with varying success. Upon hydrogenation of benzaldehyde under standard conditions, various side products were detected when the reaction was carried out in EtOH. In THF, the hydrogenation proceeded much cleaner and afforded the expected benzylalcohol and toluene. After $8 \mathrm{~h}$, a 3:1 product distribution was observed by GC-MS (95\% conversion, Table 3 , entry 6 ). This ratio remained constant also upon extending the 
reaction time to several days, indicating that benzylalcohol and toluene were formed concomitantly via independent pathways rather than consecutively. Hence, benzylalcohol does not constitute an intermediate for the full reduction of benzaldehyde to toluene. While we have currently no rationale for the catalytic $\mathrm{C}-\mathrm{O}$ bond cleavage required to form toluene, optimization of this hydrogenation process may become interesting for synthetic purposes. Nitrobenzene transformed cleanly into aniline (entry 7), and phenylacetylene gave a mixture of phenylacetylene, styrene, and ethylbenzene in 0.49:0.48:0.03 ratio after $5 \mathrm{~h}$. Semihydrogenation is not selective and after prolonged reaction times, ethylbenzene was the only product (entry 8). Benzonitrile was not hydrogenated at all and the starting material was recovered (entry 9).

Mechanistic investigations. In order to obtain mechanistic insights, we sought to prepare an activated precatalyst containing the substrate olefin in the palladium coordination sphere. Attempts to synthesize a complex with coordinated coe have failed thus far. However, successful olefin coordination was achieved when potentially chelating cyclooctadiene (cod) was stirred with the neutral complex $\mathbf{3 b}$ in the presence of $\mathrm{AgBF}_{4}$. Formation of complex $\mathbf{5}$ was confirmed by X-ray diffraction analysis of crystals that were grown in the presence of excess cod (Figure 4). 


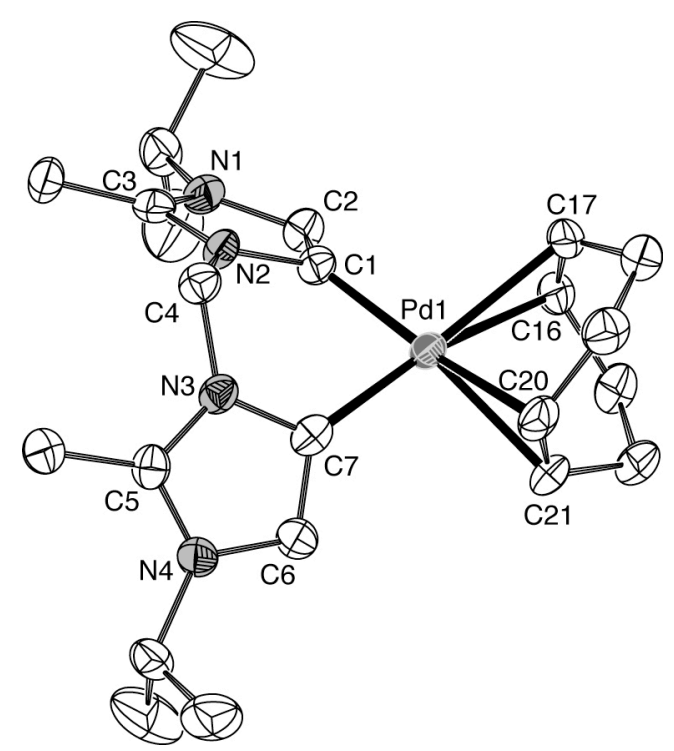

Figure 4. ORTEP representation of complex 5 (50\% probability level, hydrogen atoms, non-coordinating $\mathrm{BF}_{4}^{-}$ anions and the co-crystallized DMSO molecules omitted for clarity). Selected bond lengths ( $\AA$ ): Pd-C1 2.016(7), Pd-C7 1.989(8), Pd-C16 2.289(7), Pd-C17 2.324(7), Pd-C20 2.261(7), Pd-C21 2.295(6).

NMR spectroscopic investigation in $\mathrm{CD}_{3} \mathrm{OD}$ revealed an equilibrium between the codcontaining complex and the bissolvento complex (Scheme 2) as indicated by the appearance of signals due to unbound cod. At room temperature, this equilibrium slightly favors the cod complex (3:2 ratio, $K=3.8)$. Temperature-dependent analysis of the ratio of free and bound cod from crystalline 5 (i.e. at an exact 1:1 ratio of cod and palladium) provided the equilibrium constant and the standard enthalpy and entropy for the olefin binding and release, $\Delta \mathrm{H}^{\circ}=-22.9 \mathrm{~kJ} \mathrm{~mol}^{-1}$ and $\Delta \mathrm{S}^{\circ}=-65.6 \mathrm{~J} \mathrm{~K}^{-1} \mathrm{~mol}^{-1} \cdot{ }^{[18]}$ As catalytic experiments were run with monodentate olefins only, these factors need to be qualitatively corrected: the entropy term is expected to decrease and the equilibrium constant should shift further towards the solvento complex due to the lack of chelating effects in the monodentate alkenes.

\section{Scheme 2}



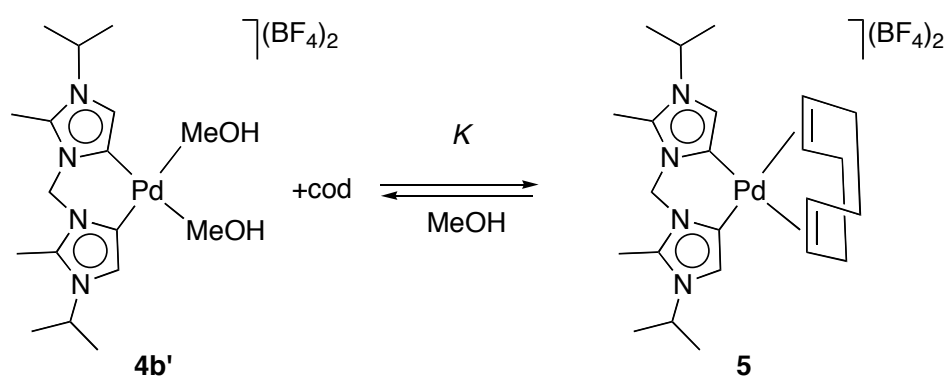

Noteworthy, ${ }^{1} \mathrm{H}$ NMR spectroscopy in deuterated MeCN or DMSO showed only the bissolvento complex, i.e. signals that are identical to those of complex $\mathbf{4 b}$, and quantitative amounts of free cod. Hence alcohols displace the olefin only partially, while $\mathrm{MeCN}$ and DMSO bind too strong to allow for olefin coordination, even when chelating cod is used. These results may provide a rationale for the inactivity of complex $\mathbf{4 b}$ in olefin hydrogenation when coordinating solvents were used ( $c f$. Table 1).

Further insights were gained from substoichiometric experiments with a 3:1 substrate/catalyst ratio using coe and complex $\mathbf{4 b}$. The runs were stopped by filtration over silica after different reaction times and analyzed by NMR spectroscopy and GC-MS. No changes were observed after 10 min, and complex $\mathbf{4 b}$ and all coe was still present. After 20 min, black particles were present and ${ }^{1} \mathrm{H}$ NMR spectroscopy confirmed decomposition of the complex to the bisimidazoluim salt (and probably an inorganic palladium salt). From GC-MS measurements, coe was hydrogenated to cyclooctane in $75 \%$. After $40 \mathrm{~min}$, the ${ }^{1} \mathrm{H}$ NMR spectrum was unchanged, yet conversions reached completion according to GC-MS. These experiments suggest that the final $25 \%$ substrate seemed to be converted at a stage where the complex was present only in trace amounts at best. Hence loss of the dicarbene ligand from complex $\mathbf{4 b}$ may generate the catalytically active heterogeneous or homogeneous species.

Distinction between heterogeneous and homogeneous catalysis is far from being trivial as it is difficult to exclude that traces of complex remaining in solution constitute the catalytically active species. ${ }^{[20]}$ Similarly, leaching of metal atoms from a heterogeneous support may lead 
to homogeneous activity. ${ }^{[21]}$ Such an event was excluded, however, in our case due to the results obtained from a mercury poisoning experiment. ${ }^{[22]}$ Stirring of a solution of complex $\mathbf{4 b}$ under hydrogen atmosphere in the presence of a large excess of mercury ( $>100$ equiv) prior to the addition of coe suppressed the catalytic activity completely.

To further confirm the heterogeneous mode of action, the catalytic reaction was monitored by GC-MS and dynamic light scattering (DLS) techniques. ${ }^{[23]}$ For this purpose, solutions containing the palladium complex $4 \mathbf{a}$ and coe were centrifuged twice to eliminate any trace of residual particles before purging the solution with $\mathrm{H}_{2}$ (1 bar). Samples were taken at regular intervals and analyzed for conversion using GC-MS and for particle growth by DLS. In a standard run (Fig. 5a), conversion was accompanied with particle growth and after $1 \mathrm{~h}$, particles with $\mathrm{rh} \approx 200 \mathrm{~nm}$ formed. The particle size gradually growed, and microsize particles were present after about $6 \mathrm{~h}$, when conversion reached about $40 \%$. Filtration of identical solutions at different stages through a nanoporous membrane after 1,2 , and $4 \mathrm{~h}$, respectively, indicated a clear correlation between conversion and the presence of particles (Fig. 5b-d). For example, filtration after 2 h (Fig. 5c) and analysis of the reaction mixture after $2.5 \mathrm{~h}$ showed the efficient removal of all nanoparticles, but not of the complex, as particle formation is resumed after some time again. Notably, catalytic activity dropped significantly in the absence of particles, and only $6 \%$ conversion was observed between the measurement at $2.5 \mathrm{~h}$ and that at $4.5 \mathrm{~h}(c f .20 \%$ conversion during the same period in the unfiltered sample, Fig. 5a). The effect is perhaps even more obvious in the run that was filtered after $4 \mathrm{~h}$. Initial conversions were rather low, probably due to the absence of particles at an early stage of the reaction. After filtration of the formed particles, the catalytic reaction essentially ceased ( $3 \%$ conversion between $4.5 \mathrm{~h}$ and $6.5 \mathrm{~h})$ and only resumed once particle growth had started again. These measurements hence suggest that formation of 
submicrometer size particle is essential for the catalytic activity, hence indicating a heterogeneous mechanism.

a)

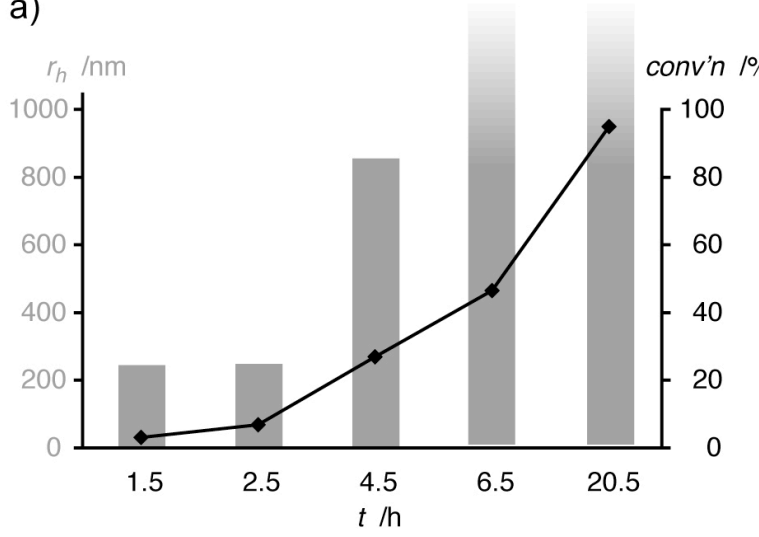

C)

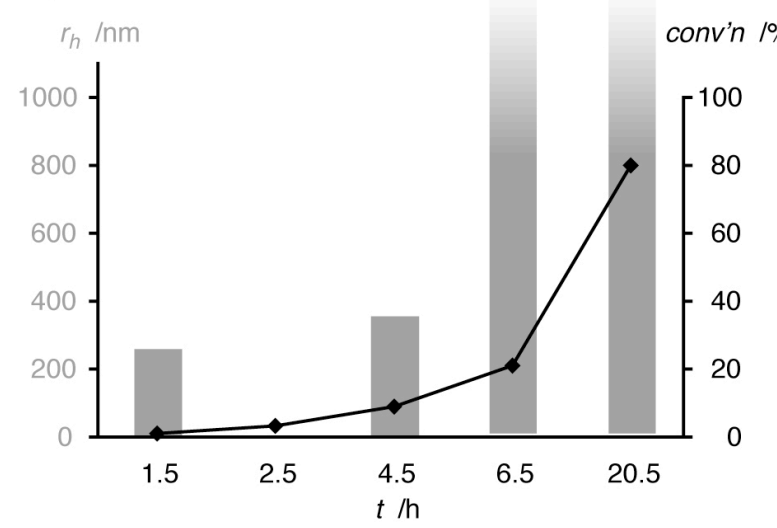

b)

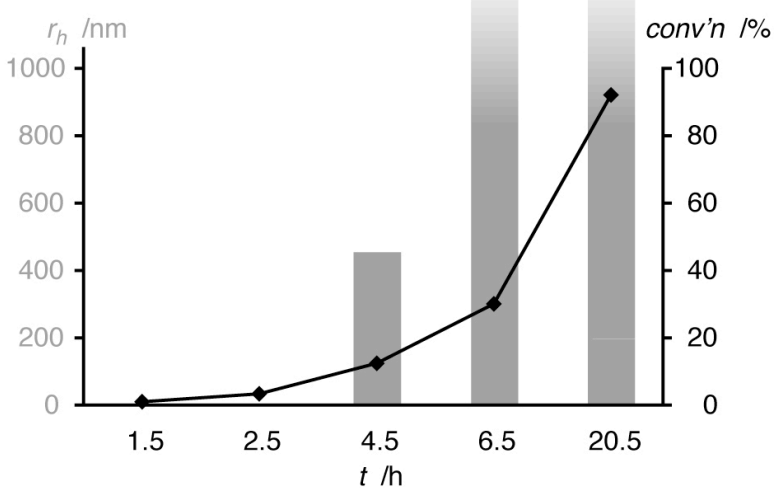

d)

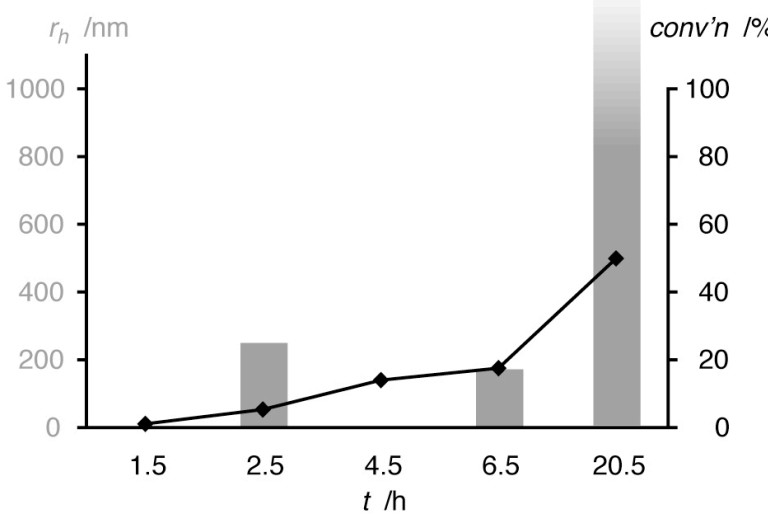

Figure 5. Correlation of particles size (grey pillars, left $\mathrm{x}$-scale) and conversion (blue diamonds, right $\mathrm{x}$-scale) for catalytic runs that were not filtered (a), and filtered after $1 \mathrm{~h}(\mathrm{~b})$, after $2 \mathrm{~h}$ (c), and after $4 \mathrm{~h}$ (d).

Taking into account all these elements, a mechanism for the activity of complexes 4 is suggested that includes $i$ ) the coordination of one (or two) olefins to the palladium center, which accounts for the inactivity of the neutral complexes $\mathbf{1}$ and $\mathbf{3}$, as well as of complex $\mathbf{4}$ in strongly coordinating solvents, ii) oxidative addition of dihydrogen and reductive $\mathrm{C}-\mathrm{H}$ bond elimination of the imidazolium salt, leading to palladium hydride species as effective precursor for the formation of colloidal palladium. ${ }^{[24]}$ Oxidative addition is obviously facilitated by the high electron density at the palladium center, imparted by the C4-bonding of 
the carbene ligand. Subsequent reductive elimination of C4-bound carbenes has been shown to be faster than that of $\mathrm{C} 2$-bound $\mathrm{NHCs},{ }^{[25]}$ presumably because of the weaker bonding of abnormal carbenes. A reactivity sequence that may model this catalyst activation step was recently disclosed by reacting the palladium complexes with chlorine rather than with hydrogen. ${ }^{[14]}$ Exposure of complexes similar to $\mathbf{4}$ to $\mathrm{Cl}_{2}$ afforded instantaneously the doubly chlorinated imidazolium salt with $\left[\mathrm{PdCl}_{4}\right]^{2-}$ as counterion. Substituting chlorine in this process with hydrogen would provide the protonated imidazolium salt, as observed in substoichiometric catalytic runs, and $\left[\mathrm{PdH}_{4}\right]^{2-}$ as precursor for palladium nanoparticles. ${ }^{[26]}$. In agreement with this model, the dicarbene complex 2 featuring normally bound NHC ligands lacks the reactivity towards oxidative addition and reductive elimination in the presence of chlorine ${ }^{[14]}$ and it is also an inefficient hydrogenation catalyst. ${ }^{[27]}$ Thus, the abnormal bonding mode of the carbene in complex 4 seems to be essential to activate the catalytic species, though it is a 'suicidal' ligand that escapes from the palladium coordination sphere during this activation process.

\section{Conclusions}

Palladium complexes comprising abnormally bound dicarbene ligands are pre-catalysts for the hydrogenation of olefins under mild conditions $\left(\mathrm{EtOH}, \mathrm{RT}, 1\right.$ bar $\mathrm{H}_{2}$, no additives such as base or co-ligand). Mechanistic investigations consistently indicate a heterogeneous mode of action, which is supported by ligand loss at an early stage of the reaction as observed in substoichiometric experiments, sigmoidal reaction kinetics, long induction periods, effective catalyst poisoning by elemental mercury, and the correlation of conversion with the presence of particles. Noteworthy, heterogeneization, which is in the present case identical to catalyst activation, requires the abnormal carbene bonding mode and is presumed to involve an oxidative $\mathrm{H}_{2}$ addition and subsequent reductive imidazolium elimination. In a broader 
context, this investigation may reflect the limitations of abnormal carbenes and of $\mathrm{N}$ heterocyclic carbenes in general as spectator ligands in hydrogenation reactions, a field where phosphines have been much more efficient ligands thus far.

\section{Experimental section}

General. The synthesis of complexes 1-4 was previously reported. ${ }^{[1,16]}$ All other reagents are commercially available and were used as received. NMR spectra were recorded on Bruker spectrometers at $25{ }^{\circ} \mathrm{C}$ (unless specified otherwise). Chemical shifts ( $\delta$ in ppm, coupling constants $J$ in $\mathrm{Hz}$ ) were referenced to external $\mathrm{SiMe}_{4}$. Elemental analyses were performed by the Microanalytical Laboratory of Ilse Beetz (Kronach, Germany).

Synthesis of 5. Cyclooctadiene $(0.54 \mathrm{~g}, 5.0 \mathrm{mmol})$ and $\mathrm{AgBF}_{4}(0.41 \mathrm{~g}, 2.11 \mathrm{mmol})$ were added to a suspension of $\mathbf{4 b}(0.60 \mathrm{~g}, 0.97 \mathrm{mmol})$ in THF. The reaction mixture was stirred for $16 \mathrm{~h}$ under exclusion of light. After filtration through Celite, the solvent was removed in vacuo to give 5 as a grey solid $(0.59 \mathrm{~g}, 94 \%)$. Recrystallization from $\mathrm{MeCN} / \mathrm{Et}_{2} \mathrm{O}$ in the presence of excess cod gave an analytically pure sample. ${ }^{1} \mathrm{H}$ NMR $\left(500 \mathrm{MHz}, \mathrm{CD}_{3} \mathrm{OD}\right): \delta$ $7.34\left(\mathrm{~s}, 2 \mathrm{H}, \mathrm{H}_{\mathrm{NHC}}\right), 6.19\left(\mathrm{~s}, 2 \mathrm{H}, \mathrm{NCH}_{2} \mathrm{~N}\right), 6.19\left(\mathrm{~s}, 4 \mathrm{H}, \mathrm{CH}_{\mathrm{COD}}\right), 4.60\left(\mathrm{sept},{ }^{3} J_{\mathrm{HH}}=6.7 \mathrm{~Hz}, 2 \mathrm{H}\right.$, $\mathrm{CHMe}_{2}$ ), 2.93-2.83 (m, 4H, $\left.\mathrm{CH}_{2} \mathrm{COD}\right), 2.74$ (s, 6H, $\left.\mathrm{C}_{\mathrm{NHC}}-\mathrm{CH}_{3}\right), 2.73-2.64$ (m, 4H, $\left.\mathrm{CH}_{2} \mathrm{COD}\right)$, $1.49\left(\mathrm{~d},{ }^{3} J_{\mathrm{HH}}=6.7 \mathrm{~Hz}, 12 \mathrm{H}, \mathrm{CH}\left(\mathrm{CH}_{3}\right)_{2}\right) .{ }^{13} \mathrm{C}\left\{{ }^{1} \mathrm{H}\right\} \mathrm{NMR}\left(101 \mathrm{MHz}, \mathrm{CD}_{3} \mathrm{OD}\right): \delta 144.2\left(\mathrm{C}_{\mathrm{NHC}}-\right.$ Me), $135.0\left(\mathrm{C}_{\mathrm{NHC}}-\mathrm{Pd}\right), 121.0\left(\mathrm{C}_{\mathrm{NHC}}-\mathrm{H}\right), 120.8(\mathrm{CH}$ $30.4\left(\mathrm{CH}_{2} \mathrm{COD}\right), 22.4\left(\mathrm{CH}-\mathrm{CH}_{3}\right), 10.0\left(\mathrm{C}_{\mathrm{NHC}}-\mathrm{CH}_{3}\right)$. Elem. anal. calcd. for $\mathrm{C}_{23} \mathrm{H}_{36} \mathrm{~B}_{2} \mathrm{~F}_{8} \mathrm{~N}_{4} \mathrm{Pd}$ (648.59): C 42.59, H 5.59, N 8.64; found: C: 42.43, H 5.72, N 8.71.

General procedure for alkene hydrogenation. A solution of catalyst precursor $(0.013 \mathrm{~g}$, $0.02 \mathrm{mmol})$ and olefin $(2 \mathrm{mmol})$ in $\mathrm{EtOH}(6 \mathrm{~mL})$ was saturated with $\mathrm{H}_{2}$ for 4 min and stirred 
at $25{ }^{\circ} \mathrm{C}$ under an atmosphere of $\mathrm{H}_{2}$. Samples $(0.1 \mathrm{~mL})$ were withdrawn at regular time intervals and filtered through a short pad of $\mathrm{SiO}_{2}$ and analyzed by GC-MS (volatile substrates) or, after solvent evaporation, by ${ }^{1} \mathrm{H}$ NMR spectroscopy.

Stoichiometric hydrogenation. A solution of catalyst precursor $(0.030 \mathrm{~g}, 0.05 \mathrm{mmol})$ and cyclooctene $(0.15 \mathrm{mmol})$ in $\mathrm{EtOH}(6 \mathrm{~mL})$ was saturated with $\mathrm{H}_{2}$ for $4 \mathrm{~min}$ and stirred at $25^{\circ} \mathrm{C}$ under an atmosphere of $\mathrm{H}_{2}$. Samples $(0.1 \mathrm{~mL})$ were withdrawn at regular time intervals and filtered through a short pad of $\mathrm{SiO}_{2}$ and analysed by GC-MS. A second aliquot $(0.5 \mathrm{~mL})$ was removed and precipitated by addition of $\mathrm{Et}_{2} \mathrm{O}(10 \mathrm{~mL})$. The brown residue was dried under vacuum and analyzed by ${ }^{1} \mathrm{H}$ NMR spectroscopy.

Dynamic Light Scattering experiments. Samples were prepared by adding EtOH $(6 \mathrm{~mL})$ to cyclooctene $(0.11 \mathrm{~g}, 1.0 \mathrm{mmol})$ and $4 \mathrm{a}(0.013 \mathrm{~g}, 0.021 \mathrm{mmol})$. The resulting suspension was stirred at RT for $30 \mathrm{~min}$ and then centrifuged $(1 \mathrm{~h}, 9000 \mathrm{rpm})$. A $3 \mathrm{~mL}$ portion from the supernatant was transferred into a quartz cell and centrifuged once more (1 h, $9000 \mathrm{rpm})$. Hydrogenation was initiated by passing $\mathrm{H}_{2}$ for $2 \mathrm{~min}$ through the solution, and the mixture was subsequently left under a steady $\mathrm{H}_{2}$ atmosphere $(1 \mathrm{~atm})$. At given time intervals, the solutions were filtered through Celite and twice through a $0.45 \mu \mathrm{m}$ filter, and then analyzed by DLS and GC-MS. The hydrodynamic radius $R_{H}$ of the particles was calculated using the Stokes Einstein relation based on average diffusion coefficients D, which were obtained from second-order cumulant analysis of the intensity correlation functions. ${ }^{[28]}$

Structure determination and refinement of the complexes. Suitable single crystals were mounted on a Stoe Mark II-Imaging Plate Diffractometer System (Stoe \& Cie, 2002) equipped with a graphite-monochromator. Data collection was performed at $-100{ }^{\circ} \mathrm{C}$ using 
Mo-Ka radiation $(1=0.71073 \AA)$. All structures were solved by direct methods using the program SHELXS-97 and refined by full matrix least squares on $\mathrm{F}^{2}$ with SHELXL-97. ${ }^{[29]}$ The hydrogen atoms were included in calculated positions and treated as riding atoms using SHELXL-97 default parameters. All non-hydrogen atoms were refined anisotropically. A semi-empirical absorption correction was applied using MULscanABS as implemented in PLATON03 ${ }^{[30]}$ Further details on data collection and refinement parameters are collected in the supporting information (Table S2).

In complexes $\mathbf{4 a}, \mathbf{4 b}$, and $\mathbf{4 c}$, one of the two $\mathrm{BF}_{4}{ }^{-}$anions $(\mathbf{4 a}, \mathbf{4 c})$ or both $(\mathbf{4 b})$ were disordered. All fluorine atoms that participate in the disorder were refined with the bond distances constraint to their theoretical values and the thermal values were constraint to be equal. In complex $\mathbf{4 b}$, also one isopropyl group is disordered over two positions, the participating atoms $\mathrm{C} 9, \mathrm{C} 9 \mathrm{a}, \mathrm{C} 10, \mathrm{C} 10 \mathrm{a}$ and the corresponding riding atoms have occupancies of 0.5 . Crystallographic data (excluding structure factors) for the structures $\mathbf{2}, \mathbf{4 a}, \mathbf{4 b}, \mathbf{4 c}$, and $\mathbf{5}$ have been deposited with the Cambridge Crystallographic Data Centre as supplementary publication nos. CCDC 782481-782485. Copies of the data can be obtained free of charge on application to CCDS, 12 Union Road, Cambridge CB2 1EZ, UK [Fax: (int.) +44-1223-336033; E-mail: deposit@ccds.cam.ac.uk].

\section{Acknowledgements}

We thank Dr. G. Savin for technical assistance, the Swiss National Science Foundation, Cost Action D4, and the Alfred Werner Foundation (Assistant Professorship to M.A) for generous financial support, and Prof. S. Gladiali for fruitful discussions.

\section{References}


[1] a) J. A. Osborn, F. J. Jardine, J. F. Young, G. Wilkinson, J. Chem. Soc. 1966, 1711; b) H. B. Kagan, Pure Appl. Chem. 1975, 43, 401; c) M. D. Fryzuk, B. Bosnich, J. Am. Chem. Soc. 1977, 99, 6262; d) R. H. Crabtree, Acc. Chem. Res. 1979, 12, 331; e) J. Halpern, Science 1982, 217, 401; f) W. S. Knowles, Acc. Chem. Res. 1983, 16, 106; g) R. Noyori, T. Ohkuma, Angew. Chem. 2001, 113, 40; Angew. Chem. Int. Ed. 2001, 40, 40.

[2] For selected reviews on NHCs as ligands, see: a) S. T. Liddle, I. S. Edworthy, P. L. Arnold, Chem. Soc. Rev. 2007, 36, 1732; b) F. E. Hahn, M. C. Jahnke, Angew. Chem. 2008, 120, 3166; Angew. Chem. Int. Ed. 2008, 47, 3122; c) A. T. Normand, K. J. Cavell, Eur. J. Inorg. Chem. 2008, 2781; d) S. Diez-Gonzalez, N. Marion, S. P. Nolan, Chem. Rev. 2009, 109, 3612; e) L. Mercs, M. Albrecht, Chem. Soc. Rev. 2010, 39, 1903.

[3] W. A. Herrmann, Angew. Chem. Int. Ed. 2002, 114, 1342; Angew. Chem. Int. Ed. 2002, $41,1290$.

[4] For few successful approaches, see: a) H. M. Lee, D. C. Smith, Z. He, E. D. Stevens, C. S. Yi, S. P. Nolan, Organometallics 2001, 20, 794; b) R. E. Douthwaite, M. L. H. Green, P. J. Silcock, P. T. Gomesc, J. Chem. Soc., Dalton Trans. 2002, 1386; c) L. D. VázquezSerrano, B. T. Owens, J. M. Buriak, Chem. Commun. 2003, 2518; d) J. W. Sprengers, J. Wassenaar, N. D. Clemtn, K. J. Cavell, C. J. Elsevier, Angew. Chem. 2005, 117, 2062; Angew. Chem. Int. Ed. 2005, 44, 2026; e) D. C. Graham, K. J. Cavell, B. F. Yates, Dalton Trans. 2006, 1768; f) S. Burling, B. M. Paine, D. Nama, V. S. Brown, M. F. Mahon, T. J. Prior, P. S. Pregosin, M. K. Whittlesey, J. M. J. Williams, J. Am. Chem. Soc. 2007, 129, 1987; g) M. Moser, B. Wucher, D. Kunz, F. Rominger, Organometallics 2007, 26, 1024; h) C. Gandolfi, M. Heckenroth, A. Neels, G. Laurenczy, M. Albrecht, Organometallics 2009, 28, 5112. 
[5] a) K. J. Cavell, D. S. McGuinness, Coord. Chem. Rev. 2004, 248, 671; b) C. M. Crudden, D. P. Allen, Coord. Chem. Rev. 2004, 248, 2247. For other bond cleavege mechanisms, see also: c) J. M. Praetorius, C. M. Crudden, Dalton Trans. 2008, 31, 4079.

[6] For selected examples, see: a) D. S. McGuinness, W. Mueller, P. Wasserscheid, K. J. Cavell, B. W. Skelton, A. H. White, U. Englert, Organometallics 2002, 21, 175; b) F. C. Courchay, J. C. Sworen, I. Ghiviriga, K. A. Abboud, K. B. Wagener, Organometallics 2006, 25, 6074; c) M. Arisawa, Y. Terada, K. Takahashi, M. Nakagawa, A. Nishida, $J$. Org. Chem. 2006, 71, 4255; d) V. L. Chantler, S. L. Chatwin, R. F. R. Jazzar, M. F. Mahon, O. Saker, M. K. Whittlesey, Dalton Trans. 2008, 2603; e) O. Saker, M. F. Mahon, J. E. Warren, M. K. Whittlesey, Organometallics 2009, 28, 1976.

[7] For examples of stable metal hydrides, see: R. F. R. Jazzar, S. A. Macgregor, M. F. Mahon, S. P. Richards, M. K. Whittlesey, J. Am. Chem. Soc. 2002, 124, 4944.

[8] For selected examples, see: a) D. S. McGuinness, M. J. Green, K. J. Cavell, B. W. Skelton, A. H. White, J. Organomet. Chem. 1998, 565, 165; b) D. S. McGuinness, K. J. Cavell, Organometallics 2000, 19, 4918; c) D. S. McGuinness, N. Saendig, B. F. Yates, K. J. Cavell, J. Am. Chem. Soc. 2001, 123, 4029; d) A. M. Magill, D. S. McGuinness, K. J. Cavell, G. J. P. Britovsek, V. C. Gibson, A. J. P. White, D. J. Williams, A. H. White, B. W. Skelton, J. Organomet. Chem. 2001, 617-618, 546; e) A. T. Normand, S. K. Yen, H. V. Huynh, T. S. A. Hor, K. J. Cavell, Organometallics 2008, 27, 3153.

[9] D. S. McGuinness, K. J. Cavell, B. W. Skelton, A. H. White, Organometallics, 1999, 18, 1596.

[10] M. Albrecht, Chem. Commun. 2008, 3601. O. Schuster, L. Yang, H. G. Raubenheimer, M. Albrecht, Chem. Rev. 2009, 109, 3445. 
[11] M. Heckenroth, E. Kluser, A. Neels, M. Albrecht, Angew. Chem. 2007, 119, 6409; Angew. Chem. Int. Ed. 2007, 46, 6293.

[12] For a recent application of normal carbene palladium complexes in catalytic hydrogenation, see: V. Jurcik, S. P. Nolan, C. S. J. Cazin, Chem. Eur. J. 2009, 15, 2509.

[13] a) S. Gründemann, A. Kovacevic, M. Albrecht, J. W. Faller, R. H. Crabtree, Chem. Commun. 2001, 2274; b) A. R. Chianese, A. Kovacevic, B. M. Zeglis, J. W. Faller, R. H. Crabtree, Organometallics 2004, 23, 2461.

[14] M. Heckenroth, A. Neels, M. G. Garnier, P. Aebi, A. W. Ehlers, M. Albrecht, Chem. Eur. J. 2009, 15, 9375.

[15] J. G. de Vries, C. J. Elsevier (eds.), Handbook of Homogeneous Hydrogenation, WileyVCH, Weinheim 2007.

[16] a) M. Heckenroth, A. Neels, H. Stoeckli-Evans, M. Albrecht, Inorg. Chim. Acta 2006, 359, 1929; b) M. Heckenroth, E. Kluser, A. Neels, M. Albrecht, Dalton Trans. 2008, 6242.

[17] a) W. A. Herrmann, J. Schwarz, M. G. Gardiner, M. Spiegler, J. Organomet. Chem. 1999, 575, 80; b) S. Ahrens, A. Zeller, M. Taige, T. Strassner, Organometallics 2006, 25, 5409; c) T. Sherg, S. K. Schneider, G. D. Frey, J. Schwarz, E. Herdtweck, W. A. Herrmann, Synlett 2006, 2894; d) A. Poulain, M. Iglesias, M. Albrecht, Curr. Org. Chem. 2011, in press.

[18] See the supporting information for details.

[19] M. S. Carpenter, W. M. Easter, J. Org. Chem. 1955, $20,401$. 
[20] a) I. W. Davies, L. Matty, D. L. Hughes, P. J. Reider, J. Am. Chem. Soc. 2001, 123, 7584; b) J. A. Widegren, R. G. Finke, J. Mol. Catal. A 2003, 198, 317; c) C. M. Hagen, J. A. Widegren, P. M. Maitlis, R. G. Finke, J. Am. Chem. Soc. 2005, 127, 4423.

[21] a) W. P. Dunsworth, F. F. Nord, J. Am. Chem. Soc. 1980, 72, 4197; b) J. G. de Vries, J. Chem. Soc. Dalton Trans. 2006, 421.

[22] a) C. Paal, W. Hartmann, Chem. Ber. 1918, 51, 711; b) D. R. Anton, R. H. Crabtree, Organometallics 1983, 2, 855; c) G. M. Whitesides, M. Hackett, R. L. Brainard, J. P. P. M. Lavalleye, A. F. Sowinski, A. N. Izumi, S. S. Moore, D. W. Brown, E. M. Staudt, Organometallics 1985, 4, 1819.

[23] a) M. J. Russel, C. White, P. M. Maitlis, J. Chem. Soc., Chem. Commun. 1977, 427; b) R. H. Crabtree, J. M. Mihelcic, J. M. Quirck, J. Am. Chem. Soc. 1979, 101, 7738; c) R. H. Crabtree, M. F. Mellea, J. M. Mihelcic, J. M. Quirck, J. Am. Chem. Soc. 1982, 104, 107; d) R. M. Laine, J. Mol. Cat. 1982, 14, 137; e) L. N. Lewis, N. Lewis, J. Am.Chem. Soc. 1986, 108, 7228; f) L. N. Lewis, J. Am Chem. Soc. 1986, 108, 743.

[24] a) S. Jansat, M. Gomez, K. Philippot, G. Muller, E. Guiu, C. Claver, S. Castillon, B. Chaudret, J. Am. Chem. Soc. 2004, 126, 1592; b) C. C. Cassol, A. P. Umpierre, G. Machado, S. I. Wolke, J. Dupont, J. Am. Chem. Soc. 2005, 127, 3298.

[25] a) D. Bacciu, K. J. Cavell, I. A. Fallis, L-1. Ooi, Angew. Chem. 2005, 117, 5416; Angew. Chem. Int. Ed. 2005, 44, 5282; b) K. J. Cavell, Dalton Trans. 2008, 6676.

[26] Catalytically active colloidal palladium may be prepared of course from much simpler molecular palladium(II) precursors. For representative examples, see: a) L. D. Rampino, K. E. Kavanagh, F. F. Nord, Proc. Natl. Acad. Sci., USA 1943, 29, 246; b) H. Hirai, H. Chawanya, N. Toshima, Bull. Chem. Soc. Jpn. 1985, 58, 682; c) L. A. Fowley, D. 
Michos, X.-L. Luo, R. H. Crabtree, Tetrahedron Lett. 1993, 34, 3075; d) A. Roucoux, K. Philippot in ref. 15, p 217; e) Y. Tsuji, T. Fujihara, Inorg. Chem. 2007, 46, 1895.

[27] As an alternative mechanism to the oxidative addition and reductive elimination sequence, the postulated palladium hydride intermediate along with the observed imidazolium salts may be formed by heterolytic $\mathrm{H}_{2}$ splitting across the $\mathrm{Pd}-\mathrm{C}_{\text {carbene }}$ bond.

[28] R. Pecora (ed.), Dynamic Light Scattering, Plenum Press, New York, 1985, pp 420.

[29] G. M Sheldrick, Acta Cryst. 2008, A64, 112.

[30] A. L. Spek, J. Appl. Cryst. 2003. 36, 7. 


\section{Catalytic Hydrogenation Using Abnormal N-Heterocyclic Carbene Palladium}

\section{Complexes: Catalytic Scope and Mechanistic Insights}

Marion Heckenroth, Vsevolod Khlebnikov, Antonia Neels, Peter Schurtenberger, Martin Albrecht*

Abnormally C4-bound N-heterocyclic carbene palladium complexes (see picture) are effective precursors for the catalytic hydrogenation of a variety of olefins. Detailed mechanistic investigations indicate that catalyst activation involves oxidative $\mathrm{H}_{2}$ addition and subsequent imidazolium reductive elimination as pictured, thus providing a heterogeneously operating catalyst.

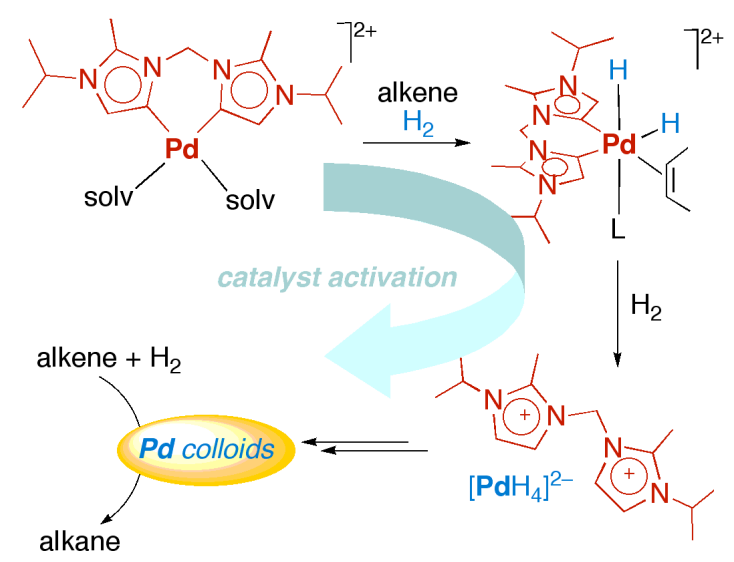

